\title{
O papel do juiz hermeneuta e parcialmente positivo
}

\author{
THE ROLE OF THE JUDGE HERMENEUT PARTLY \\ POSITIVE \\ * Marcos Antonio Striquer Soares \\ ** Pedro Guilherme Kreling Vanzella
}

Resumo: O artigo descreve o trabalho dinâmico do operador do direito, sobretudo do interprete juiz, considerando o círculo hermenêutico e a ampliação de sentidos pré-concebidos pelo texto normativo a culminar na reconstrução da norma. Aponta para o juiz parcialmente positivo como protagonista deste cenário de reconstrução de sentidos, principalmente como concretizador dos objetivos da República consagrados na Constituição Federal. Analisa os poderes instrutórios do juiz como meio legítimo previsto pelo ordenamento para atuação do juiz parcialmente positivo e a garantia ao contraditório e o dever da motivação das decisões como limitadores dessa atuação reconstrutiva.

Palavras-chave: Hermenêutica Jurídica. Imparcialidade. Parcialidade Positiva.

Abstract: The paper describes the dynamic work of the operator's right above the legal interpreter, precisely in expanding the senses preconceived normative text to culminate in the reconstruction of meaning. Points to the judge partially positive as the protagonist of this scenario reconstruction of meanings, mainly as concretizing the fundamental rights enshrined in the democratic state. Analyzes the powers of the court investigation is archived as a legitimate means provided by law for partially positive role of the judge and ensuring the contradictory and duty reasons for decisions such as limiting activities reconstructive senses.

Keywords: Legal Hermeneutics. Impartiality. Positive Bias.

* Mestre e Doutor em Direito do Estado/Direito Constitucional pela PUC/SP. Professor de Direito Constitucional na Graduação em Direito, na Especialização em Direito do Estado e no Mestrado em Direito Negocial da UEL/PR. Email:marcosstriquer@uol. com.br

** Mestre em Direito Negocial pela UEL/PR. E-mail: pedroguilhermevanzella @gmail.com 


\section{INTRODUÇÃO}

O Poder Judiciário é, sem dúvida, responsável pela concretização e promoção dos objetivos da República previstos no art. $3^{\circ}$ da Constituição Federal, como a igualdade social, econômica e cultural. Logo, é evidente que o juiz assume papel relevante frente à concretização desses objetivos, assim como os demais operadores do Direito, porquanto é inarredável concluir que a desigualdade social deságua no processo judicial.

Essa responsabilidade, é importante dizer, não decorre apenas da inércia ou imperícia do Poder Legislativo na promulgação de leis. Sobretudo em tempos de evolução vertiginosa de valores e de anseios da sociedade. A evolução do Direito não se revela apenas na edição de novos comandos normativos, senão também a partir da reconstrução de sentidos a partir do próprio texto normativo vigente, pela dialética processual e pelo contraditório (diálogo) travado no processo judicial.

E não basta ao intérprete do Direito reverberar os sentidos pré-concebidos dos textos normativos ou justapor os sentidos dados pelo texto ao fato concreto. Exige-se que vá além da pré-compreensão do texto normativo, que considere todo o contexto hermenêutico, a desigualdade social, cultural e econômico refletida no litígio.

Com efeito, o presente estudo se propõe a fazer uma releitura do princípio da imparcialidade do juiz no Estado Constitucional ${ }^{1}$, na forma proposta por Artur Cesar de Souza, a partir de seu texto “A parcialidade positiva do juiz”, publicado em 2008. Faz-se necessário estabelecer a diferença entre a parcialidade negativa, considerada o objeto do conceito clássico do princípio da imparcialidade e a parcialidade positiva como necessária à concretização dos objetivos da República.

\section{O INTÉRPRETE E A “RECONSTRUÇÃO DE SENTIDOS”}

Inicialmente, necessário observar que, ao se falar de interpretação ou hermenêutica jurídica, é preciso considerar, de antemão e ainda que de forma sumária, que a norma não se confunde com textos normativos. Muito menos

\footnotetext{
${ }^{1}$ Estado Constitucional aqui é entendido segundo a doutrina de Konrad Hesse, vale dizer, a força normativa da Constituição, que tem a sua força motriz ou sua "força vital ou germe" na própria realidade cultural, social, política e econômica de uma nação. Tanto porque uma "disciplina normativa contrária a essas leis não logra concretizar-se”. HESSE, Konrad. A força normativa da constituição. Trad. Gilmar Ferreira Mendes. Porto Alegre: Sergio Antonio Fabris Editor, 1991 p. 18.
} 
mantêm correspondência ${ }^{2}$ entre si. Singelamente, a norma é o produto da interpretação sistemática dos textos normativos. De forma mais precisa, a norma representa o "sentido construído a partir da interpretação sistemática de textos normativos”. (ÁVILA, 2013, p. 33).

Tanto que poderá haver norma sem um texto normativo correspondente ou, ainda, um texto normativo donde se extraia mais de uma norma. Não se encontra no ordenamento jurídico, por exemplo, texto normativo específico e que disponha expressamente sobre o princípio da segurança jurídica. Todavia, é inegável que, por força de interpretação sistemática de textos normativos se constitui em norma basilar do Estado Democrático de Direito.

O artigo $5^{\circ}$, inciso LV da Constituição Federal, por sua vez, é exemplo clássico de um único texto normativo que emana mais de uma norma, porquanto dispõe sobre o direito ao contraditório e à ampla defesa. Dele se extrai a norma do prazo razoável para defesa, livre acesso aos documentos do processo, paridade de armas, entre outros.

O importante desta reflexão é conceber que a tarefa do intérprete não se resume apenas e tão somente a compreender o conteúdo gramatical do texto normativo ou proceder à mera "subsunção do fato à norma”. Sua arte vai muito além de descrever um significado previamente dado pelo texto. Segundo Ávila, a interpretação é “um ato de decisão que constitui a significação e os sentidos de um texto” (ÁVILA, 2013, p. 34).

Não se nega que o texto contenha palavras ou expressões que são previamente conhecidas pelo intérprete, que lhe trazem determinadas expectativas acerca do quanto dito. Entretanto, interpretar significa "reajustar a expectativa e fazer concluir o texto na unidade de um pensamento, a partir de outra expectativa de sentido” (GADAMER, 2000, p. 141). Trata-se de um círculo hermenêutico ${ }^{3}$ do todo para a parte e novamente desta para o todo.

\footnotetext{
${ }^{2}$ No sentido de que "sempre que houver um dispositivo haverá uma norma, ou sempre que houver uma norma deverá haver um dispositivo que lhe sirva de suporte”. (ÁVILA, 2013, p. 33).

3 Segundo Alexandre Araújo Costa, ao invés de círculo a metáfora mais correta seria espiral, pois "passamos do particular para o contexto e do contexto para o particular de uma forma cíclica e contínua, motivo pelo qual chamamos esse processo de círculo hermenêutico. Todavia, uma metáfora mais adequada para descrever a compreensão seria a imagem da espiral, pois, a cada volta, em vez de retornarmos ao mesmo lugar, avançamos para níveis maiores de complexidade e de aprofundamento. [...] Trata-se de um processo infinito, sendo impossível afirmar que, em um dado momento, teremos chegado à conclusão definitiva. (apud, GOMES, 2008, p. 130).
} 
A arte de interpretar, com efeito, pressupõe o intérprete como ser humano, em toda sua complexidade, experiências, cultura, formação, visão do mundo, enfim, como alguém inserido na sociedade e capaz de formar uma précompreensão do texto objeto de seu estudo. De outro lado, exige deste mesmo ser humano um ato de humildade, de desprendimento, pois, "quem pretende compreender um texto está disposto a deixar que o texto lhe diga algo" (GADAMER, 2000, p. 145).

Gadamer acentua:

Por isso, uma consciência formada hermeneuticamente deve estar disposta a acolher a alteridade do texto. Mas tal receptividade não supõe a "neutralidade", nem a autocensura, mas implica a apropriação seletiva das próprias opiniões e preconceitos. É preciso precaver-se das próprias prevenções para que o texto mesmo apareça em sua alteridade e faça valer sua verdade real contra a própria opinião. (GADAMER, 2000, p. 145).

O intérprete não busca apenas confirmar suas convicções ou antecipações, mas guiado por uma intenção metodológica, busca "tomar consciência delas para controlá-las e obter, assim, a reta compreensão a partir das coisas mesmas” (HEIDEGGER, apud, GADAMER, 2000, p. 146).

Considerando, pois, a pré-compreensão do texto a partir de um contexto vivido pelo intérprete e pela própria sociedade naquele dado momento interpretativo, é certo que o intérprete "parte de algo" pré-concebido. Com efeito, supera-se a ideia de que interpretar seja apenas um ato de construir sentidos, mas, a rigor, num ato de reconstrução a partir do próprio texto normativo e de outros sentidos já constituídos ou preexistentes.

Segundo Ávila:

[...] interpretar é construir a partir de algo, por isso significa reconstruir: a uma porque utiliza como ponto de partida os textos normativos, que oferecem limites à construção de sentidos; a duas porque manipula a linguagem, à qual são incorporados núcleos de sentidos, que são, por assim dizer, constituídos pelo uso, e preexistem ao processo interpretativo individual. (ÁVILA, 2013, p. 36).

A importância de conceber o intérprete jurídico, precisamente o juiz, como um hermeneuta reconstrutor de sentidos é que permite a conclusão por um Poder Judiciário que "concretiza o ordenamento jurídico diante do caso concreto" (ÁVILA, 2013, p. 37). 
A esse respeito Gomes destaca que quanto mais vasto for o horizonte do hermeneuta, maiores serão as possibilidades de compreensão e, por consequência, maior será a possibilidade de encontrar a solução "mais adequada para o contexto em que a norma jurídica resultante da interpretação será aplicada” (GOMES, 2008, p. 131).

Gomes conclui:

Se este contexto é o do Estado Democrático de Direito, o intérprete está vinculado ao dever de interpretar o texto jurídico em consonância com os princípios, valores e objetivos que integram o referido paradigma estatal, pois é nesse sentido que estão as expectativas da sociedade em relação ao Direito vigente em tal contexto. (GOMES, 2008, p. 132).

A toda evidência, é mais adequado falar em reconstrução de sentidos quando se versa sobre a interpretação jurídica. Sobretudo porque o intérprete não pode desprezar o que já está construído pelo ordenamento jurídico, pelo processo legislativo que o antecedeu e até mesmo pela jurisprudência. A rigor, e acima de tudo, deve ele "interpretar os dispositivos constitucionais de modo a explicitar suas versões e significados de acordo com os fins e os valores entremostrados na linguagem constitucional” (ÁVILA, 2013, p. 38).

A função do intérprete, sobretudo a do intérprete em sentido estrito 4 , vai muito além, como se vê, da mera subsunção do fato à norma ou de um observador do procedimentalismo jurídico ${ }^{5}$. Efetivamente, se revela como postura substancialista, consistente na concretização dos valores que motivam e balizam o Estado Democrático de Direito.

Logo, trata-se de um ato de inteligência que jamais poderá ser realizado de forma mecânica ou mesmo burocrática. O Poder Judiciário, portanto, assume a responsabilidade pela concretização dos objetivos da República e inseridos no art. $3^{\circ}$ da Constituição Federal, vale dizer, eliminar as desigualdades sociais, culturais e econômicas.

\footnotetext{
${ }^{4}$ Peter Häberle, citado por Gomes, "destaca duas categorias de interpretes: os interpretes em sentido lato e os interpretes em sentido estrito. [...] os interpretes em sentido estrito, a figura daqueles que exerce a jurisdição ou poder jurisdicional, isto é, o juiz, a fim de ressaltar as relevantes possibilidades que se lhe apresentam para participar, por meio de sua atividade hermeneutica, na construção do Estado Democrático de Direito”. (2008, p. 361).

5 "As posturas procedimentalistas não reconhecem um papel concretizador à jurisdição constitucional, reservando para esta apenas a função de controle das regras do jogo 'democrático'”. (STRECK, 2011, p. 52).
} 
Não significa dizer, entretanto, que o intérprete esteja livre para expressar as suas próprias convicções morais, as suas conveniências políticas, ou mesmo para atuar como um ativista judicial. Afinal, só se pode falar em concretização de direitos quando houver, efetivamente, coerência de sentidos em relação aos direitos fundamentais consagrados pela Constituição.

Aliás, esta coerência de sentidos é que torna eficaz o próprio direito concretizado. Quanto mais intensamente o sentido dado ao texto normativo estiver suportado por princípios superiores, isto é, com a constituição, tanto mais será eficaz e efetivamente concretizado (ÁVILA, 2013, p. 151/2).

Gomes afirma que o Estado Democrático de Direito exige do juiz e de todo o Poder Judiciário a máxima conexão com a hermenêutica constitucional, a fim de que a própria Constituição ganhe sentido e os direitos fundamentais sejam concretizados (GOMES, 2008, p. 370).

\subsection{O juiz como hermeneuta}

É inegável a importância e o papel do juiz que sobressai da análise de todo o contexto hermenêutico sobredito. Ainda mais quando, no exercício de sua função, não apenas interpreta o texto normativo, mas igualmente o conflito social representado na lide e toda a sorte de consequências nele envolvidas ${ }^{6}$.

Interpretar os fatos e o controvertido dos autos do processo é um trabalho de hermenêutica, no qual o juiz busca construir e comunicar sentidos. Não apenas em relação à norma aplicável, mas de todo o contexto axiológico daquela relação posta em julgamento. Mais do que isso, deve o juiz "reconhecer todas as formas de vida humana e articulações de cada uma de suas respectivas imagens de mundo" (GADAMER, 2000, p. 23).

Com efeito, o juiz não deve ser alguém alienado do contexto ou convívio social onde ocorre, efetivamente, o fenômeno jurídico ${ }^{7}$. Não há como conceber um "juiz dissociado do contexto social, marginalizado da sociedade, purificado de qualquer concepção ideológica, social, cultural e psicológica” (SOUZA, 2008, p. 136).

\footnotetext{
${ }^{6}$ Nas palavras de Tércio Sampaio Ferraz Jr.: “[...] A realidade, o mundo real, não é um dado, mas uma articulação lingüística mais ou menos uniforme num contexto social” (apud, SOUZA, 2008, p. 151). 7 Vem a calhar, neste sentido, o argumento de Gomes: “Assim, ninguém conseguirá compreender o fenômeno jurídico isolando-se. Isso pelas seguintes razões: a) tal fenômeno se dá no convívio social; b) O intérprete, queira ou não, jamais poderá, por si só, construir a compreensão do Direito, pois situa-se ele em um meio social, cultural linguistico que fala sobre o Direito e vivencia experiências identificadas como sendo jurídicas. Vive, portanto, num contexto que se lhe apresenta, também como se fosse um texto. E todo texto exige interpretação para que possa fazer sentido" (2008, p. 131).
} 
Ora, será exatamente a partir de tais concepções que formará sua précompreensão sobre o conflito a decidir e as normas a serem aplicadas. Sem dúvida, um juiz ‘marginalizado’ e ‘cego’ às desigualdades sociais transportadas à relação jurídica processual não estará apto a reconstruir sentidos porque não conhece o que está construído e sequer o próprio objeto cognoscente.

Em última análise, não estabelecerá Justiça. O juiz não alcançará sequer o sentido do texto normativo, jamais alcançará a norma, sobretudo se considerado o Direito em sua Tríplice Perspectiva (fato, valor e norma) ${ }^{8}$, pois os "valores são acessíveis somente por meio da intuição emocional”, de modo que, para compreendê-los é preciso vivenciá-los (GOMES, 2008, p. 104).

Gomes acentua que "a atenção sobre a dimensão humana do juiz é de extrema relevância quando se percebe e se defende que, de problemas humanos, só pode entender e dar solução justa quem compreende os seres humanos” (2008, p. 361). Para Artur Cesar de Souza, aliás, é “utópica” a pretensão de um juiz que não seja cidadão, que possuam suas próprias e personalíssimas convicções de mundo ${ }^{9}$.

Ocorre, todavia, que boa parte da doutrina desencoraja a análise feita a partir destas premissas, receosos de que se estaria com isso violando o princípio da imparcialidade do juiz. Entretanto, essa posição se mostra absolutamente equivocada, pois a imparcialidade do juiz não pressupõe um “juiz asséptico”, que deve "atuar como um eunuco político, econômico e social, desinteressado do mundo fora do tribunal” (GRIFFITH, apud SOUZA, 2008, p. 136).

Forçoso, então, enfrentar o princípio da imparcialidade e compreender o seu real sentido. Necessário será ultrapassar as pré-compreensões dadas exclusivamente pelo texto normativo e ampliar os horizontes da norma que the resulta.

\subsection{A "releitura” do princípio da imparcialidade do juiz frente à reconstrução de sentidos}

O princípio da imparcialidade do juiz é exemplo de norma que não possui previsão em texto normativo específico, tal qual o da segurança jurídica já comentado. A rigor, a imparcialidade do juiz é fruto de interpretação

\footnotetext{
${ }^{8}$ Segundo Miguel Reale "encontraremos sempre estes três elementos, onde quer que se encontre a experiência jurídica: - fato, valor e norma. Donde podemos concluir, dizendo que a palavra Direito pode ser apreciada, por abstração, em tríplice sentido, segundo três perspectivas dominantes: O Direito como valor [...]; o Direito como norma; o Direito como fato social”. (1994, p. 509).

9 SOUZA, Artur Cesar. Op Cit. 2008, p. 151.
} 
sistemática de diversos textos normativos, sobretudo a partir de Tratados Internacionais, como o Pacto Internacional de Direitos Civis e Políticos (art. 14, I), como também, e originariamente, na Declaração Universal dos Direitos Humanos (art. 10) e, por fim, a partir da Constituição Federal (art. 5, XXXVII e LIII, art. 95, parágrafo único e, art. 37).

A Constituição Italiana, ao contrário da brasileira, prevê expressamente no texto normativo a garantia à imparcialidade positiva do juiz, conforme se depreende do art. 111: "La giurisdizione si attua mediante il giusto processo regolato dalla legge. Ogni processo si svolge nel contraddittorio tra le part, in condizione di paritá, davanti a giudice terzo e imparziale. La legge ne assicura la ragionevole durata" ${ }^{\text {. }}$.

Merece destaque o dispositivo constitucional italiano, sobretudo porque no mesmo comando normativo insere, junto à garantia da imparcialidade $e$ juiz natural, as garantias ao processo justo regulado pela lei ${ }^{11}$, à paridade de armas, ao contraditório e à duração razoável do processo. A princípio, o legislador constituinte italiano demonstra, em certa medida, a relação de imbrincamento entre as garantias ali descritas.

Com efeito, a garantia à imparcialidade do juiz é indispensável a um processo justo, assim como será para proporcionar a paridade de armas.

Importa reconhecer, portanto, que a imparcialidade do juiz é uma garantia ou um princípio universal, nascido, sobretudo no pós II Guerra Mundial como direito fundamental e ao fito de assegurar a concretização de tantos outros direitos igualmente fundamentais. Cintra, Grinover e Dinamarco afirmam que "a imparcialidade do juiz é uma garantia de justiça para as partes" (CINTRA, GRINOVER e DINAMARCO, 2005, p. 54).

Entretanto, a imparcialidade tem sido interpretada de forma equivocada por boa parte da doutrina e até mesmo pelos tribunais, que vêem na produção da prova ex officio pelo juiz uma violação ao princípio da imparcialidade.

Ocorre que esta concepção desafia uma releitura do instituto, nos moldes propostos por Artur Cesar de Souza, na obra já citada “A Parcialidade Positiva do Juiz”. Sobretudo porque a imparcialidade vista sob o ângulo da

\footnotetext{
${ }^{10}$ Em tradução livre: “A jurisdição se realiza mediante o processo justo regulado pela lei. Todo o processo se desenvolve a partir do contraditório entre as partes, em condições de paridade, diante de um juiz terceiro e imparcial. A lei garante uma duração razoável ao processo.

11 "Identifica-se o justo processo com o conjunto de exigências que permitem ao juiz, como terceiro (im)parcial, ditar uma decisão conforme o direito, em um processo público que garanta um debate equilibrado entre as partes e a observância da presunção de inocência do acusado; isto é, '(...) conforme a los princípios que se extraen del conjunto de derechos y garantias procesales constitucionalizadas'” (SOUZA, 2008. p. 222).
} 
neutralidade ou da inércia do magistrado, ao contrário de garantir um processo justo, a contrário senso, favorece a injustiça.

Artur Cesar de Souza aponta que o juiz não pode ser neutro e, citando Zaffaroni, lembra que "não existe a neutralidade ideológica, salvo na forma de apatia, irracionalismo ou decadência do pensamento, que não são virtudes dignas de ninguém e menos ainda de um juiz" (ZAFFARONI apud SOUZA, 2008, p. 139).

Sob o ponto de vista da neutralidade, a imparcialidade nega o caráter discursivo e dialético do processo e impede o exercício interpretativo de acordo com a nova hermenêutica, vale dizer, torna-se um obstáculo à reconstrução de sentidos. Afinal, "o sujeito que reflete, mesmo nas ciências da compreensão, (...) não consegue evadir-se do contexto histórico-efeitual de sua situação hermenêutica, visto que sua compreensão sempre está implicada nesse acontecer" (GADAMER, apud SOUZA, 2008, p. 141).

Com efeito, a imparcialidade, considerada como ausência de parcialidade e como princípio estruturante da atividade jurisdicional, deve ser "redesenhada" a partir daquela e "reconstruída" sob duas perspectivas, uma parcialidade negativa e outra parcialidade positiva (SOUZA, 2008, p. 229/230).

A primeira, denominada de parcialidade negativa, é clássica e consiste naquelas hipóteses em que há vinculação dos interesses do juiz aos interesses de uma das partes. Trata-se de um odioso favorecimento em decorrência de um interesse pessoal do juiz (SOUZA, 2008, p. 233). Representa, portanto, aquilo que a Declaração Universal dos Direitos Humanos (art. 10) e a própria Constituição Federal quiseram abolir do processo jurisdicional.

Citando Melo Ribeiro, Artur Cesar de Souza afirma que a imparcialidade, vista sob a perspectiva da parcialidade negativa, impõe uma série de proibições, como “(...) de favorecer ou dar preferência, a proibição de discriminar ou perseguir, a proibição de intervir no processo quando pessoalmente interessado" (2008, p. 231).

Todavia, não se pode falar em "processo justo” apenas sob a perspectiva de proibições ou abstenções. É preciso considerar, pois, um juiz processualmente ativo $^{12}$, que elimina as diferenças sociais refletidas na relação jurídica processual e favorece a paridade de armas ao fito de alcançar a decisão justa.

${ }^{12}$ Destaca-se que esta expressão, ao menos para efeito do presente trabalho, não guarda qualquer relação com o que se convencionou denominar na doutrina de ativismo judicial. 
Enfim, é necessário analisar a imparcialidade também sob o ponto de vista de um juiz parcialmente positivo.

Somente um juiz parcialmente positivo, que considera a realidade social das partes refletidas na relação jurídica processual e que, a partir dela estabelece um processo hermenêutico de reconstrução de sentidos, poderá concretizar os direitos e as garantias fundamentais do Estado Democrático de Direito.

Souza aponta a concretização dos objetivos fundamentais da República Federativa do Brasil como uma função essencial do juiz parcialmente positivo:

A função positiva, por sua vez, informa materialmente o agir do magistrado, para que ele leve em consideração no desenvolvimento válido e regular da relação jurídica processual os aspectos instrumentais necessários para a construção de uma sociedade mais justa, solidária, erradicando-se a pobreza e as desigualdades sociais, econômicas, culturais etc. (SOUZA, 2008, p. 233/234).

Logo, para alcançar a justeza de suas decisões, deve o juiz parcialmente positivo eliminar as desigualdades sociais refletidas na relação jurídica processual e, não apenas permitir condições idênticas de produção de provas, mas igualmente determinar a produção de outras tantas quantas forem necessárias para o fiel cumprimento de seu mister.

\section{A PARCIALIDADE POSITIVA E OS PODERES INSTRU- TÓRIOS DO JUIZ}

Não raro, o juiz se depara empiricamente com situações de extrema desigualdade processual. Seja pelo desequilíbrio técnico e econômico dos advogados, seja pela hipossuficiência técnica e econômica da própria parte. Essa experiência revela que a garantia constitucional a um tratamento igualitário entre as partes é meramente formal.

Exigir do juiz que se mantenha alheio, inerte ou mesmo neutro em relação à tamanha desigualdade é admitir a ineficácia do princípio da igualdade, além de um processo injusto e regido não pela justeza mas, sobretudo, pelo poder econômico ${ }^{13}$. Tanto porque essa desigualdade, inegavelmente, acaba por

\footnotetext{
13 "O que se pretende, na verdade, não é estabelecer uma justiça dos pobres em contraposição à justiça dos mais abastados economicamente, mas, sim, formatar um Poder Judiciário acessível a todos com igualdade de condições e estrutura. Deseja-se romper com as perspectivas, ainda recentes, das indiferenças em relação à realidade do sistema judiciário. 'Fatores como diferenças entre os litigantes em potencial no acesso prático ao sistema, ou a disponibilidade de recursos para enfrentar o litígio, não eram (e não são) sequer percebidos como problemas””. (SOUZA, 2008, P. 208).
} 
obstaculizar em grande medida uma decisão justa e conectada com os princípios e garantias fundamentais do Estado Democrático de Direito.

Exatamente em casos deste jaez atua o juiz parcialmente positivo a fim de encontrar "meios legítimos conferidos pelo ordenamento jurídico, e que não são poucos" e promover ou viabilizar a paridade de armas, ou melhor, "promover o desenvolvimento da relação jurídica processual penal ou civil com base nos princípios democráticos fundamentais previstos na Constituição Federal brasileira de 1988” (SOUZA, 2008, p. 211).

Dentre os meios legítimos conferidos pelo ordenamento jurídico ao juiz parcialmente positivo estão os poderes instrutórios previstos, sobretudo, no Código de Processo Civil, com destaque ao artigo 130 que assim dispõe: caberá ao juiz, de ofício ou a requerimento da parte, determinar as provas necessárias à instrução do processo, indeferindo as diligências inúteis ou meramente protelatórias.

Há quem diga, como Enrico Tulio Liebman, por exemplo, que rejeitam um juiz parcialmente positivo e os seus poderes instrutórios. Segundo essa corrente, tais poderes devem ser desencorajados por refletir uma tendência paternalística e que não guarda relação com as funções do Poder Judiciário (BEDAQUE, 2011, p. 115).

Outros argumentos utilizados por doutrinadores como Frederico Marques e Arruda Alvim, é de que a iniciativa probatória do juiz violaria o princípio da imparcialidade, pois o levaria a crer no objeto de sua própria investigação. (BEDAQUE, 2011, p. 114).

Entretanto, esse enfoque negativo da imparcialidade é de todo equivocado, pois não considera a perspectiva positiva e acaba por aceitar a violação da própria garantia que visam assegurar. Afinal, "não seria parcial o juiz que, tendo conhecimento de que a produção de determinada prova possibilitará o esclarecimento de um fato obscuro, deixe de fazê-lo, com tal atitude, acabe beneficiando a parte que não tem razão?” (BEDAQUE, 2011, p. 116).

A leitura do princípio da imparcialidade apenas sob a perspectiva negativa, além de ensejar em sua própria violação, impede a concretização dos objetivos fundamentais da República e afastaria a decisão final da máxima conexão com a hermenêutica constitucional.

Essa visão equivocada do princípio da imparcialidade tem contribuído para uma tradição de juízes passivos, meros espectadores e temerosos de qualquer iniciativa, ainda que estejam convencidos do contrário. 
O processualista italiano Sergio Charlon, em outras palavras, afirma que inibir a iniciativa probatória do juiz, a pretexto de se preservar a imparcialidade, não concretiza as garantias constitucionais, mas apenas revela o processo como um jogo em que não vence a parte que tem razão, mas aquela que possui um advogado mais hábil, vale dizer, aquela que se sagra campeã.

Affermare che Il provvedimento ufficioso che ammette La prova “aggira” Le preclusioni "a favore" di una parte e "a danno" dell'altra significa preoccuparsi del fatto che La parte há torto in fatto e che spera di vincere la causa per l'errore commesso dall'avversario nel non dedurre in tempo La sua prova viene "danneggiata” dal successivo intervento del giudice. Tutto cio non há che fare con le garanzie costituzionali, bensì con vetusta concezione del processo come un giuco dove non Vince La parte che ha ragione, ma la parte che si può avvalere del campione, cioè dell'avvocato, più abile. (RePro 219, p. 132$)^{14}$.

Ora, o processo não pode ser visto como um jogo, muito menos como um jogo de soma zero, em que o vencedor se sagra campeão na exata medida da derrota do outro. Pelo contrário, o processo deve ser norteado pelo princípio da cooperação ${ }^{15}$ entre as partes, incluindo também aí o juiz.

É certo, portanto, que a iniciativa probatória do juiz, baseado na perspectiva da parcialidade positiva, não apenas concretiza os direitos fundamentais ou os objetivos fundamentais do Estado Democrático de Direito como também solidifica e reforça a garantia/princípio/direito ao tratamento igualitário entre as partes, à imparcialidade e, ainda, torna efetivo o direito material.

Nestes termos, Bedaque conclui:

A participação do juiz na formação do conjunto probatório, determinando a realização das provas que entender necessárias ao esclarecimento dos fatos

\footnotetext{
${ }^{14}$ Em tradução livre: “Afirmar que o provimento de ofício que ordena a produção da prova enseja na preclusão em favor de uma das partes e em prejuízo a outro significa preocupar com o fato de que a parte a parte espera vencer a causa a partir do erro cometido pelo adversário por não requerer a tempo a produção da prova que virá prejudicada pela intervenção do juiz. Isto tudo não guarda relação com a garantia constitucional, bem assim como concessão de um processo como um jogo onde não vence a parte que tem razão, mas a parte que pode se sagrar campeã, isto é, do advogado mais esperto".

${ }^{15}$ Princípio incluído expressamente na redação do art. $8^{a}$ do projeto do novo CPC: "As partes e seus procuradores têm o dever de contribuir para a rápida solução da lide, colaborando com o juiz para a identificação das questões de fato e de direito e abstendo-se de provocar incidentes desnecessários e procrastinatórios”.
} 
deduzidos pelas partes, de forma nenhuma afeta sua imparcialidade. Agindo assim, demonstra o magistrado estar atento aos fins sociais do processo. A visão publicista deste exige um juiz comprometido com a efetivação do direito material. Isto é, o juiz pode, a qualquer momento, e de ofício, determinar sejam produzidas provas necessárias ao seu convencimento. Trata-se de atitude não apenas admitida pelo ordenamento, mas desejada por quem concede o processo como instrumento efetivo de acesso à ordem jurídica justa. (BEDAQUE, 2011, p. 119).

Considerando, portanto, que as regras jurídicas estão sempre "centradas na finalidade que lhes dá suporte ou nos princípios que lhes são axiologicamente sobrejacentes" 16 é correto afirmar que a atuação do juiz assentado nos artigos 130 e 131 do Código de Processo Civil, longe de violar o princípio da imparcialidade, atende aos princípios constitucionais axiologicamente sobrejacentes à referida norma processual, como a igualdade entre as partes, a pacificação social, a busca pela verdade real, a segurança jurídica, entre outros.

\subsection{A iniciativa probatória e o dever de motivação}

Conforme já alinhavado, a perspectiva de um juiz parcialmente positivo não pressupõe, a toda evidência, a sua alforria em relação à motivação das decisões ou mesmo o autoriza fragmentar o direito ao contraditório. Aliás, também estas se revelam em garantias essenciais do Estado Democrático de Direito (CF, art. 5 , LV, e art. 93, IX).

Nesta esteira, Bedaque aponta que "a melhor maneira de preservar a imparcialidade do magistrado é submeter sua atividade ao princípio do contraditório e impor-lhe o dever de motivar suas decisões [...]” (2011, P. 117). Com efeito, sempre que houver a iniciativa oficial pela produção de determinada prova, haverá de se observar o contraditório, oportunizando a manifestação das partes em igualdade de condições.

De outro lado, o dever de motivação da decisão judicial é a expressão do trabalho hermenêutico praticado pelo juiz. Revela, por assim dizer, o caminho

\footnotetext{
16 “As regras são normas imediatamente descritivas, primariamente retrospectivas e com pretensão de decidibilidade e abrangência, para cuja aplicação se exige a avaliação da correspondência, sempre centrada na finalidade que lhes dá suporte ou nos princípios que lhes são axiologicamente sobrejacentes, entre a construção conceitual da descrição normativa e a construção conceitual dos fatos” (ÁVILA, 2013, p. 85).
} 
percorrido pelo juiz e que o levou à conclusão por aquela determinada sentença. A reconstrução de sentidos dos textos normativos é revelada exatamente pela motivação consignada na decisão.

É através da motivação das decisões que se avalia a exigida máxima conexão com os objetivos fundamentais do Estado Democrático de Direito.

Logo, a garantia à imparcialidade não se restringe às proibições, pelo contrário, nos deveres. Não é razoável proibir ou mitigar os poderes instrutórios do magistrado, pois, como dito, não favorecerá a parte que tem razão, mas aquela mais hábil ou em melhores condições de litígio.

O que garante a eficácia da imparcialidade são os deveres do juiz, tanto no atuar de forma parcialmente positiva equilibrando o litígio e permitindo que ambos as partes tenham as mesmas condições de produção da prova, como também no observar o contraditório e no dever de motivar as decisões.

\section{CONSIDERAÇÕES FINAIS}

A Ciência do Direito não se resume à análise ou descrição do significado do texto normativo. Vai além. É resultado do estudo e da apreensão dos sentidos conferidos ao próprio texto pelo intérprete. O significado não é dado pelas palavras, mas pelo resultado da interpretação, da hermenêutica.

Gadamer concebe que todo intérprete possui uma pré-compreensão do texto e, na medida em que aprofunda o seu estudo amplia a sua visão do objeto compreendido ou, ainda, a ele estabelece novos sentidos.

É certo que as palavras permitem uma pré-compreensão do texto. O intérprete parte desse conhecimento prévio dado pelas palavras e de sua própria experiência de vida, assim como da própria história. Mas é a partir da hermenêutica, da interpretação do conjunto e do contexto que orbitam as palavras, que se extrai o significado.

Com efeito, uma sentença não se resume à mera subsunção do fato à norma ou apenas na declaração do significado do texto normativo frente ao fato controvertido. Mais do que isso, a sentença constrói sentidos antes não compreendidos.

Frente a este raciocínio, da dinâmica da compreensão e da construção de sentidos, a sentença será tanto mais compreendida e aceita quanto mais coerente ou mais próxima se coadunar com os direitos constitucionais fundamentais. Precisamente quanto mais se aproximar dos princípios constitucionais e dos objetivos do Estado Democrático de Direito. 
O juiz, portanto, assume papel de relevante importância para a Ciência do Direito, sobretudo no exercício da jurisdição em época marcada pelas desigualdades sociais refletidas na relação jurídica processual. Numa época em que o hipossuficiente e a sociedade contemporânea, explícita e implicitamente, exigem do intérprete do Direito uma postura pró-ativa, uma atitude marcada pela busca da verdade e garantidora dos direitos fundamentais.

O juiz deve despir-se da figura de mero espectador do conflito e atuar de forma parcialmente positiva, garantindo a concretização dos objetivos da República e dos princípios e garantias constitucionais fundamentais, contribuindo para a construção de sentido ao ordenamento jurídico. Deve, sobretudo, garantir a paridade de armas e instruir o processo ao fito de alcançar a pacificação social pela compreensão e acordo no objeto.

É preciso destacar, todavia, que o juiz parcialmente positivo não viola a garantia fundamental da imparcialidade. Ao contrário, a concretiza no plano fático e objetivo. Tanto porque repele a perniciosa e interesseira parcialidade negativa, que busca o favorecimento de uma parte em detrimento da outra. O juiz parcialmente positivo não pende a uma das partes, senão exclusivamente a fim de garantir a igualdade de tratamento (CPC, art. 125, I), a paridade de armas e a busca pela verdade real.

$\mathrm{O}$ ordenamento jurídico, especialmente as legislações processuais, autoriza o exercício da parcialidade positiva do juiz, como se vê, a título de exemplo, na disposição do artigo 130 do Código de Processo Civil, que autoriza o juiz “de ofício” determinar a produção de provas necessárias à instrução do processo. No mesmo norte, é o que se compreende da disposição do inciso VIII do artigo $6^{\circ}$ do Código de Defesa do Consumidor, que reserva à discricionariedade do juiz a inversão do ônus da prova no caso concreto.

A necessidade de se considerar e incentivar a parcialidade positiva do juiz na solução dos conflitos contemporâneos, todavia, não significa autorizar decisões sem a devida motivação, dado que esta igualmente se caracteriza como garantia fundamental do jurisdicionado (CF, art. 93, IX c/c CPC, art. 131, in fine).

Quanto mais estreita for a relação entre os argumentos com os princípios fundamentais menor será a indignação com o resultado prolatado pelo juiz. Vale dizer, somente essa estreita relação permitirá a efetiva pacificação social, pois, antes de tudo, permite a compreensão. 


\section{REFERÊNCIAS}

ÁVILA, Humberto. Teoria dos Princípios. 14 ed. São Paulo: Malheiros, 2013.

BEDAQUE, José Roberto dos Santos. Poderes Instrutórios do Juiz. 6 ed. São Paulo: Revista dos Tribunais, 2011.

CINTRA, Antonio Carlos de Araújo; GRINOVER, Ada Pellegrini; DINAMARCO, Cândido Rangel. Teoria Geral do Processo. 21 ed. São Paulo: Malheiros, 2005.

CHIARLONI, Sergio. Giusto Processo. Revista de Processo, ano 38, vol. 219, maio/2013, p. 119/152.

GADAMER, Hans-Georg, in ALMEIDA, Custódio Luíz Silva de. Hermenêutica filosófica: nas trilhas de Hans-Georg Gadamer. Porto Alegre: EDIPUCRS, 2000.

GOMES, Sergio Alves. Hermenêutica Constitucional. Curitiba: Juruá, 2008.

SOUZA, Artur César de. A parcialidade positiva do juiz. São Paulo: Revista dos Tribunais, 2008.

STRECK, Lenio Luiz. Hermeneutica Jurídica e(m) Crise: uma exploração hermenêutica da construção do Direito. 10 ed. Porto Alegre: Livraria do Advogado Editora, 2011.

Artigo recebido em: 16/06/2015 Aprovado para publicação em: 19/08/2015

Como citar: SOARES, Marcos Antônio Striquer. VANZELLA, Pedro Guilherme Kreling. O papel do juiz hermeneuta e parcialmente positivo. Revista do Direito Público. Londrina, v.10, n.2, p.111-126, mai./ago. 2015. DOI: 10.5433/1980-510X.2015v10n2p111. 